THE COLLAPSE OF DEFECT CASCADES TO DISLOCATION LOOPS*

M. A. Kirk, I. M. Robertson**, M. L. Jenkins***, C. A. English ${ }^{+}$,

T. J. Black*** and J. S. Vetrano**

Materials Science and Technology Division

Argonne National Laboratory

Argonne, IL 5.3439

**University of Illinois, Urbana, IL 61801

$* * *$ University of Oxford, Oxford OX1 3PH, England

${ }^{+}$AERE Harwe11, OX11 ORA, England

Received by OSTI

MAY 191986

CONF-860421--39

DE86 010519

April 1986

\begin{abstract}
The submitted manuxcripe has been authored by a contractor of the U.S. Government under contrect No. W-31-109-ENG-38. Accordingly, the U. S. Government retains a nonexclusive, royalty-free license to publish or reproduce the published form of this or reproduce the published form of this con s. Govern or allow or humper.
\end{abstract}

\title{
DISCLAIMER
}

\begin{abstract}
This report was prepared as an account of work sponsored by an asency of the Unitod States Government. Neither the United States Government nor any agency theroof, nor any of their employees, makes any warranty, express or implied, or ascumes any lezal liability or responsibility for the accuracy, completeness, or usefulness of any information, apparatus, product, or process disclowed, or represents that its use would not infringe privately ownod rights Reference herein to any specific commercial product, process, or service by trade name, trademark, manufacturer, or otherwise does not necestarily conatitute or imply its endorsement, recommendation, or favoring by the United States Government or any ageacy thereof. The views and opinions of authors expremed herein do act nocenarily state or refloct those of the Unitod States Government or any asency thereof.
\end{abstract}

Submitted to the Second International Conference on Fusion Reactor Materials, April 13-17, 1986, Chicago, Illinois.

*Work supported by the U. S. Department of Energy, BES-Materials Sciences, under Contracts W-31-109-Eng-38 (ANL) and AC09-76ER01198 (Univ, of IL). 


\title{
THE COLLAPSE OF DEFECT CASCADES TO DISLOCATION LOOPS*
}

\author{
M. A. Kirk, I. M. Robertson**, M. L. Jenkins***, C. A. English ${ }^{+}$, \\ T. J. Black*** and J. S. Vetrano** \\ Materials Science and Technology Division \\ Argonne National Laboratory \\ Argonne, IL 60439 \\ **University of Illinois, Urbana, IL 61801 \\ ***University of Oxford, Oxford ox1 3PH, England

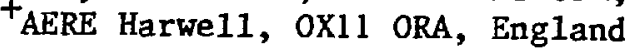

Apri1 1986

The submitred menuxcript has been authored
by a contractor of the U.S. Government
under contract No. W-31-109-ENG-38.
Accordingly, the U. S. Government retains a
nonexclusive, royelty-free license to publish
or reproduce the publisted form of this
contribution, or allow others to do $\$$, for
U. S. Government purposes.

Submitted to the Second International Conference on Fusion Reactor Materials, April 13-17, 1986, Chicago, Illinois.

*Work supported by the U. S. Department of Energy, BES-Materials Sciences, under Contracts $W-31-109-E n g-38$ (ANL) and ACO9-76ER01198 (Univ. of IL). 
THE COLLAPSE OF DEFECT CASCADES TO DISLOCATION LOOPS*

\author{
M. A. Kirk, I. M. Robertson**, M. L. Jenkins***, C. A. English ${ }^{+}$, \\ T. J. Black*t* and J. S. Vetrano** \\ Materials Science and Technology Division \\ Argonne National Laboratory \\ Argonne, IL 60439 \\ **University of Illinois, Urbana, IL 61801 \\ *** University of Oxford, Oxford OX1 $3 \mathrm{PH}$, England \\ AERE Harwel1, OX11 ORA, England
}

We review a number of experiments that we have recently performed to investigate the collapse of defect cascades to dislocation loops. This important ion and neutron irradiation phenomenon has been studied with in situ ion bombardment in the Argonne National Laboratory High Voltage Electron Microscope - Ion Accelerator Facility at temperatures of 30 and $300 \mathrm{~K}$ in $\mathrm{Cu}_{3} \mathrm{Au}, \mathrm{Cu}$, and $\mathrm{Fe}$, and 30,300 and $600 \mathrm{~K}$ in $\mathrm{Ni}$. These experiments have demonstrated that individual defect cascades collapse to dislocation loops athermally at $30 \mathrm{~K}$ in some materials ( $\mathrm{Ni}, \mathrm{Cu}$ and $\mathrm{Cu}_{3} \mathrm{Au}$ ), while in another material (Fe) only overlapped cascades produced dislocation loops. A slight sensitivity to the irradiation temperature is demonstrated in $\mathrm{Cu}_{3} \mathrm{Au}$ and $\mathrm{Fe}$, and a strong dependence on the irradiation temperature is seen in $\mathrm{Ni}$. This phenomenon of cascade collapse to dislocation loops in metals at $30 \mathrm{~K}$ provides an understanding for previous neutron irradiation data. The more detailed dependencies of the collapse probability on material, temperature, bombarding ion dose, ion energy and ion mass contribute much information to a thermal spike model of the collision cascade which we will describe.

*Work supported by the U. S. Department of Energy, BES-Materials Sciences, under Contracts W-31-109-Eng-38 (ANL) and AC09-76ER01198 (Univ. of IL). 


\section{THE COLLAPSE OF DEFECT CASCADES TO DISLOCATION LOOPS*}

M. A. KIRK, I. M. ROBERTSON**, M. L. JENKINS***, C. A. ENGLISH ${ }^{+}$, T. J. BLACK $* * *$ and J. S. VETRANO**, Materials Science and Technology Division Argonne National Laboratory, Argonne, IL 60439

**University of Illinois, Urbana, IL 61801

$* * *$ University of Oxford, Oxford OXI $3 \mathrm{PH}$, Ergland

tAERE Harwell, OX11 ORA, England

\section{Introduction}

We highlight in this paper some of the results of an ongoing experimental program of the past several years in which the above authors participate. This program is principally designed to investigate the collapse of defect cascades to dislocation loops. The primary tool for this investigation is transmission electron microscopy, especially using in situ fon bombardment in the Argonne National Laboratory High Voltage Electron Microscope - Ion Accelerator Facility. Special sample stages have allowed ion irradiations and electron microscopy at temperatures over the range of 30 to $600 \mathrm{~K}$.

Defect cascades are formed in metals under fast neutron or ion bombardment. Typically hundreds of vacancy and interstitial pairs are formed in such cascades, within $10^{-12}$ second of the primary recoil event, and over a volume of $10 \mathrm{~nm}$ diameter. The fate of these defects and how they affect material properties depends critically on the metal and the izradiation temperature. Often many of these defects cluster to form dislocation loops and stacking fault tetrahedra which are visible in the transmission electron microscope. These extended defects are important as point defect sinks and sources, as potential nucleation sites for voids or second phases, and they contribute to embrittlement and creep. It has long been known that the

\footnotetext{
*Work supported by the U. S. Department of Energy, BES-Materials Sciences, under Contracts W-31-109-Eng-38 (ANL) and AC09-76RR01198 (Univ. of IL).
} 
vacancy population in a defect cascade can collapse to form a dislocation loop under irradiation near room temperature [1]. This has been convincingly demonstrated in the ordered alloy $\mathrm{Cu}_{3} \mathrm{Au}$ irradiated both with ions and with neutrons [2]. We will show in this paper that this collapse process also takes place in some metals at an irradiation temperature of $30 \mathrm{k}$, and therefore that many dislocation loops form athermally from defect cascades within $10^{-11}$ second.

In the first part of this paper we review a completed systematic study of cascade collapse in the ordered alloy $\mathrm{Cu}_{3} \mathrm{Au}$. This summary is based on a more complete paper to be published elsewhere [3]. Three different ions and two energies were chosen for the irradiations to study the effect of cascade size and energy density. Two irradiation temperatures were chosen: one below stage I (30 K), where no long-range thermally activated point defect migration can occur, and one above stage III $(300 \mathrm{~K})$ where all point defects are mobile. The advantage of carrying out the experiment in $\mathrm{Cu}_{3} \mathrm{Au}$ is that information both on loop formation and on the location and the spatial characteristics of the cascades may be obtained through a study of the disordered zones created at all cascade sites. This technique also eliminates uncertainties introduced by errors in microscope magnification and in ion dosimetry.

In the second part of this paper we report some results from a study in progress on the probabilities for cascade collapse to loops in $\mathrm{Fe}$, $\mathrm{Ni}$ and $\mathrm{Cu}$ as functions of irradiation temperature and Ion dose. Self ions of energies of 50 and $100 \mathrm{keV}$ were employed to simulate cascades produced by fast neutrons. Iron, nickel and copper were chosen to represent a possible range of cascade collapse probabilfties based on an interpretation of resistivity damage rate data in $\mathrm{Fe}$ at $5 \mathrm{~K}$ under fast neutron bombardment [4]. These and other neutron data suggest that loops form from individual cascades produced 
at $5 \mathrm{~K}$ with increasing probability from $\mathrm{Fe}$ to $\mathrm{Ni}$ to $\mathrm{Cu}$ and that the probability increases with dose in $\mathrm{Fe}$, and possibly to a lesser extent in Ni. We have found this interpretation to be consistent with our own earlier results in $\mathrm{Fe}[5]$.

\section{Experimental Procedures}

Well ordered foils of $\mathrm{Cu}_{3} \mathrm{Au}$ with thickness $<35 \mathrm{~nm}$ were formed by vapor deposition and heat treatment. All specimens had 〈001〉 foil normals. Two batches of specimens were irradiated with $\mathrm{Ar}^{+}, \mathrm{Cu}^{+}$and $\mathrm{Kr}^{+}$ions at both 50 and $100 \mathrm{keV}$ to doses of $10^{11}$ ions $/ \mathrm{cm}^{2}$. The first of these batches was implanted at room temperature at AERE Harwell on the commercial Lintott ion implantation system and the second at $30 \mathrm{~K}$ on the HVEM-Accelerator Facility at Argonne National Laboratory [6]. Those specimens irradiated at room temperature were observed using a JEOL JEM1OOB transmission electron microscope at Oxford, while those irradiated at low temperatures were examined both in situ on the Argonne EM7 HVEM and subsequently on return to oxford in the $100 \mathrm{kV}$ instrument. The HVEM was operated at an accelerating potential of $300 \mathrm{kV}$, below the threshold for the production of electron radiation damage in $\mathrm{Cu}_{3} \mathrm{Au}$. Under typical illumination conditions of our experiments the maximum temperature rise of the specimens due to local beam heating effects was estimated always to be < $10 \mathrm{~K}$, using the expression given by Fisher [7]. Disordered zones created in $\mathrm{Cu}_{3} \mathrm{Au}$ in all cascades initiated by incident heavy-ions of energy $>10 \mathrm{keV}$ can be rendered visible as dark regions against the lighter, well-ordered background by forming dark-field images using a superlattice reflection of type $\bar{g}=\langle 110\rangle$. Disiocation loops produced by the collapse of some cascades were imaged using fundamental reflections of type $\bar{g}=\langle 220\rangle$. The defect yieid under any irradiation condition was obtained by comparing micrographs of the same region of foil imaged in superlattice and in 
fundamental reflections. The process of loop identification was carried out without reference to the micrographs showing disordered zones. Later a careful comparison of the locations of the disordered zones and of the loops confirmed that all loops were associated with disordered zones, and allowed a direct determination of the defect yield. Examples of the procedure are shown in Fig. 1, where for clarity only one micrograph of each type is displayed. In practice as many as 20 fundamental micrographs of each area were analyzed. Sample folls of commercially pure $\mathrm{Fe}$ and high purity $\mathrm{Ni}$ and $\mathrm{Cu}$ were produced from bulk material and electropolished using standard techniques. All experiments were performed in the High-Voltage Electron Microscope Accelerator Facility at Argonne National Laboratory. Samples were irradiated in situ with self lons at dose rates near $3 \times 10^{10}$ ions $/\left(\mathrm{cm}^{2} \mathrm{sec}\right)$ and at temperatures of 30,300 and $600 \mathrm{~K} \pm 2 \mathrm{~K}$. The relative accuracy of ion dosimetry among various irradiations reported here is $10 \%$. The absolute accuracy of ion dosimetry is believed to be about $20 \%$ and is currently under investigation using the disordered zone technique in $\mathrm{Cu}_{3} \mathrm{Au}$. Electron micrographs were taken at the irradiation temperatures as a function of ion dose and following annealing, often in the same sample area. The HVEM was operated at voltages below the threshold for electron damage in the foils: $200 \mathrm{keV}$ for $\mathrm{Fe}$ and $300 \mathrm{keV}$ for $\mathrm{Ni}$ and $\mathrm{Cu}$.

Dislocation loops were imaged in thin regions of the foil $(30-40 \mathrm{~nm})$ using strong 2-beam or very slightly s-positive (small positive deviation from Bragg condition) diffraction conditions. Images were recorded in dark field with operating diffraction vectors known to image most of all loops produced in these metals under these irradiation conditions: $\overline{\mathrm{g}}=\langle 200\rangle$ for all Frank loops in fcc $\mathrm{Cu}$ and $\mathrm{Ni}[8], \bar{g}=\langle 110\rangle$ in bcc Fe [5]. The smallest loops resolvable varied between 1 and $2 \mathrm{~nm}$ depending on metal, foil surface quality 
and sample stage temperature. Identification and densities of loops were measured independently by 2 or 3 researchers. Both characteristic black-white and sharp black spot images were counted. Sizes of loop images were also determined in some experiments. Results and Discussion

A comparison of the defect yields in $\mathrm{Cu}_{3} \mathrm{Au}$ for both the room and low temperature irradiation conditions are given in Table 1. Clearly, cascade coliapse to dislocation loops occurs even at $30 \mathrm{~K}$ where vacancies and interstitials are thermally immobile. Additionally it was discovered that there was no change in the defect yields measured on samples irradiated at low temperatures upon warming them to room temperaturc. All defect yields obtained from the room temperature irradiated specimens are seen to be significantly higher than those obtained from their low temperature counterparts. No significant changes in defect yield were observed on increasing the ion energy from 50 to $100 \mathrm{keV}$ at either irradiation temperature. An increase in defect yield with increasing ion mass was clearly observed in the results of room temperature irradiations and between $\mathrm{Ar}^{+}$and $\mathrm{Cu}^{+}$(or $\mathrm{Kr}^{+}$) irradiations at low temperature. Based on this evidence we conclude that collapse must occur during the phase of collision cascades when extensive vacancy motion is possible, that is the so-called thermal spike phase that occurs within about $10^{-11}$ second of cascade initiation. A sensitivity to the lattice temperature and cascade energy density (bombarding ion mass) is qualitatively explained within a thermal spike model [3]. While the above results for $\mathrm{Cu}_{3} \mathrm{Au}$ were determined at a single low ion dose (isola:ed cascades), the effect of increasing dose was investigated in $\mathrm{Cu}$ and $\mathrm{N} 1$. The results of a self ion bombardment in $\mathrm{Ni}(100 \mathrm{keV})$ at room temperature is illustrated qualitatively in the micrograph series of Fig. 2. Vacancy 
dislocation loops in the exact same area are imaged at each dose. (It has been determined in many earlier experiments [1] that vacancy loops are formed in many metals by low dose fon irradiation in thin foils at room temperature.) Arrowed loops are not found in the micrographs at the next highest doses. A saturation of the loop densities in $\mathrm{Cu}$ and $\mathrm{Ni}$ (measured from the micrographs of Fig. 2 and others not shown) is suggested in Fig. 3 for room temperature irradiations. (Representative error bars for density variation within one micrograph and among determinations by several researchers are shown in this and following figures. No correction was made for the presence of subcascades; all loops were counted.) Also note from Fig. 3 that vacancy dislocation loops are formed in $\mathrm{Ni}$ at $300 \mathrm{~K}$ at a rate of about one third of the initial rate in $\mathrm{Cu}$. Subcascades were observed to form less often in $\mathrm{Ni}$ than $\mathrm{Gu}$ at $100 \mathrm{keV}$, and preliminary size distributions (not shown) indicate that loops in $\mathrm{Ni}$ are smaller than in $\mathrm{Cu}$.

The saturation behavior of loop density with self ion dose at $100 \mathrm{keV}$ is probably accomplished by loop coalescence. Loops that seem to disappear, as in Fig. 2 (arrowed), are generally quite small. Their disappearance is usually accompanied by the appearance of a new, somewhat larger, loop within about $10 \mathrm{~nm}$ of the old loop site. Also, some loops appear to move slightly ( $<5 \mathrm{~mm}$ ) and become la"ger. Both of these observations indicate the occurrence of loop coalescence or the resuits of nearby cascade events as the dose increases.

The Increase in loop density in $\mathrm{Ni}$ with $50 \mathrm{keV}$ self-ion dose at $30 \mathrm{~K}$ is shown qualitatively in Fig. 4. Due to changing local diffraction conditions it was not possible to follow the same sample area as a function of dose at 30 $\mathrm{K}$ or upon annealing to $300 \mathrm{~K}$. Different areas representative of each dose are instead shown. Again a saturation behavior of the loop density was measured 
and found to be simflar to that observed in the $300 \mathrm{k}$ irradiation data (compare Figs. 6 and 7).

The dependence of the loop production rate (at relatively low self-ion doses) on Irradiation temperature is shown in $\mathrm{Ni}$ in Fig. 5. The production rates at 30 and $300 \mathrm{~K}$ were reproduced in 2 runs at each temperature. Only one experiment at $600 \mathrm{~K}$ has been performed to date. No obvious loop annealing occurred at $600 \mathrm{k}$, so this data reflects the true (within error) loop production rate. The difference in loop production rates at 30 and $300 \mathrm{~K}$ is about a factor of 2. This difference easily exceeds the error in the loop counting method $n$ any given micrograph (representative error bars in Fig. 5), but also well exceeds an observable difference in loop resolution at the two irradiation temperatures. The liquid HE sample stage is more stable at room temperature than it is with flowing cold gas. There is a shift of $25 \%$ of the defects to smaller sizes $(1.0-2.0 \mathrm{~nm})$ at $300 \mathrm{~K}$, some of which may be a real temperature effect, the bulk of which is probably a resolution effect. The difference in loop production rates at 30 and $600 \mathrm{~K}$ may not be outside the effect of a loss of resolution of small loops at $30 \mathrm{~K}$. However, the differences between $300 \mathrm{~K}$ and $30 \mathrm{~K}$ and between $300 \mathrm{~K}$ and $600 \mathrm{~K}$ appear to be real.

In Table 2 a summary is given of the loop production rates for the three elements under the irradiation conditions we have investigated to date. The NI values are taken from the linear fits to the low dose points. The Cu value at $100 \mathrm{keV}(300 \mathrm{~K}$ ) is from the linear portion of the curve in Fig. 3 and the value at $50 \mathrm{keV}(30 \mathrm{~K})$ is from a single dose point. Uncertainties in the $\mathrm{NI}$ and $\mathrm{Cu}$ values average 0.03 . The $\mathrm{Fe}$ values are previously published $[5,9]$, where a measurable yield is found only at higher doses $\left(\sim 10^{13}\right.$ ions $\left./ \mathrm{cm}^{2}\right)$. The loop yleld in $\mathrm{Cu}$ at $30 \mathrm{~K}$ is surprisingly low and must be confirmed vy another 
experiment. The value is also less certain than others in the table due to a change in ion dosimetry methods. However there is no doubt that individual defect cascades collapsed to vacancy dislocation loops in $\mathrm{Cu}$ and $\mathrm{Ni}$ at $30 \mathrm{~K}, \mathrm{a}$ temperature below which the free migration of interstitials or vacancies does not occur. Thus the formation of these loops is attributed to a plocess occurring during the thermal spike phase of the cascade lifetime $\left(\sim 10^{-11} \mathrm{sec}\right)$.

A measurable loop yield occurring only at much higher doses in Fe indicates that most individual self-ion cascades in $F e$ do not collapse to loops. Thus in Fe, the cascade energy density, defect density or thermal spike lifetime is insufficient to result in significant loop formation. At higher doses in $\mathrm{Fe}$, with overlapping cascades, loops are formed, probably due to higher defect density or longer thermal spike lifetimes in the overlap case.

A comparison among the three elements of loop yield versus dose is shown in Fig. 6 for room temperature irradiations ( $100 \mathrm{keV}$ self ions), and in Fig. 7 for irradiations at $30 \mathrm{~K}$ (50 keV self ions). In both figures the linear behavior (slope $n=1$ ) indicates an isolated loop production rate which is constant in dose. The slopes $\mathrm{n}<1$ at high defect densities in $\mathrm{Cu}$ and $\mathrm{Ni}$ are predominantly due to saturation behavior such as loop coalescence. The slope $\mathrm{n}=0.7 \mathrm{in} \mathrm{Fe}$ at $300 \mathrm{~K}$ (Fig. 6) may also be due to a saturation type behavior. The slope $\mathrm{a}=1.5$ in $\mathrm{Fe}$ at $30 \mathrm{~K}$ (Fig. 7) is probably the net result of a low probability for isolated cascade collapse (linear loop production rate, slope $\mathrm{n}=1$ ) combined with a quadratic loop production rate (slope $n=2$ ) due to simple overlap of two defect cascades resulting in one dislocation loop.

The differences in loop production rates among elements and between 30 and $300 \mathrm{~K}$ for any one element (Table 2) can be qualitatively explained within a thermal spike model for the evolution of the defect cascade. This model 
allows for a sufficient energy density and cascade lifetime to permit the defect motion required for the formation of vacancy dislocation loops. The difference among the three elements may be explained by differences in the average thermal spike lifetimes. The difference with irradiation temperatures, 30 and $300 \mathrm{~K}$, may be explained by a more rapid quenching of the thermal spike at $30 \mathrm{~K}$ and thus a lower probability of loop formation, as observed in $\mathrm{Cu}_{3} \mathrm{Au}$.

The room temperature yields, or loop production rates, in $\mathrm{Fe}, \mathrm{Ni}$ and $\mathrm{Cu}$ can be compared with recent literature values. If our Cu yield could be corrected for subcascades, at the $100 \mathrm{keV}$ incident self-ion energy, it would probably agree closely with the $30 \mathrm{keV}$ result $(0.4-0.5)$ of Stathopoulos [8]. This latter work is probably the most accurate yield determination in $\mathrm{Cu}$. The Fe yield at $300 \mathrm{~K}$ agrees rather well with some recently reported results of Kitagawa, et al [10]. However, our Ni yield disagrees with those of Robinscn [11] and Kitagawa [10]. The Robinson yie1d of 0.44 loops per incident $80 \mathrm{keV}$ self ion was determined with a microscope of higher resolution, but reported size distributions are in approximate agreement with ours, leaving the bulk of the difference unexplained. The Kitagawa yield of 0.9 loops per incident 65 $\mathrm{keV}$ self ion, and size distribution peaking between 0.5 and $1.0 \mathrm{~nm}$ with no defect sizes $>1.6 \mathrm{~nm}$, we feel are unreliable results due to their use of the weak beam technique. It is known that imaging and sizing sma11 loops is most reliably performed and interpreted using strong 2-beam or slightly s-positive conditions (small positive deviation from Bragg conditions) [8,12].

Fina11y, a correlation can be made with the resistivity data of low temperature $(5 \mathrm{~K})$ fast neutron bombardment in these pure metals [4]. The socalled negative curvature in the resistivity production rate, observed to occur markedly in $\mathrm{Fe}$ and less so in $\mathrm{Ni}$, may be due to vacancy loop formation 
with cascade overlap at higher neutron doses, and increasing nonlinearly with dose. The change in resistivity per vacancy upon loop formation (as suggested by Dunlap et al. [4]) could explain this negative curvature. Our TEM evidence in Fe strongly supports this. In $\mathrm{Ni}$ the continued linearity of loop production with dose, (Figs. 3, 6 and 7) to doses much higher than in $\mathrm{Cu}$, may be due to offsetting effects of loop coalescence and additional loop production with cascade overlap. Resistivity would be more sensitive to the overlap effect, and thus explain a slight negative curvature in the resistivity production rate in $\mathrm{Ni}$. $\mathrm{Cu}$ shows no TEM evidence for a cascade overlap effect, but strong loop coalescence. This is in agreement with a lack of negative curvature in the resistivity data of neutron bombarded $\mathrm{Cu}$ (at $5 \mathrm{~K}$ ). 


\section{References}

[1] Jäger, W., J. Mícrosc. Spectrosc. Electron. 6 (1981) 437.

[2] Jenkins, M. L. and English, C. A., J. Nucl. Mater. $108 \& 109$ (1982) 46.

[3] Black, T. J., Jenkins, M. L., English. C. M. and Kirk, M. A., to be published in the Proceedings of the Royal Society.

[4] Dunlop, A., Pande, B. M., Böning, K., Rosner, P. and Schaefer, H. E., J. Nucl. Mater. $108 \& 109$ (1982) 83.

[5] Robertson, I. M., Kirk, M. A. and King, Wayne E., Scripta Met. 18 (1984) 317.

[6] Taylor, A., Wallace, J. R., Ryan, E. A., Philippides, A., and Wrobel, J. R. (1981) Nucl. Inst. Methods 189, 211 .

[7] Fisher, S. B., 1970, Rad. Eff. 5, 239.

[8] Stathopoulos, A. y., Phii. Mag. A44 (1981) 285.

[9] Kirk, M. A., Robertson, I. M., King, Wayne E., Ryan, E. A. and Philippides, A., Mat. Res. Soc. Symp. Proc. 41 (1985) 319.

[10] Kitagawa, K., Yamakawa, K., Fukushima, H., Yoshiie, T., Hayashi, Y., Yoshida, H., Shimomura, Y. and Kiritani, M., J. Nucl. Mat. $133 \& 134$ (1985) 395.

[11] Robinson, T. M. and Jenkins, M. L., Phil. Mag. A43 (1981) 999.

[12] Katerbau, K.-H., Dr. rer. nat. Thesis, Univ. of Stuttgart, Stuttgart 1978. 
Table 1. Comparison of yield values from low temperature $(30 \mathrm{~K})$ and room temperature $(300 \mathrm{~K})$ irradiated specimens.

\begin{tabular}{lcccccr}
\hline & $\begin{array}{c}50 \mathrm{keV} \\
\mathrm{Ar}^{+}\end{array}$ & $\begin{array}{c}50 \mathrm{keV} \\
\mathrm{Cu}^{+}\end{array}$ & $\begin{array}{c}50 \mathrm{keV} \\
\mathrm{Kr}^{+}\end{array}$ & $\begin{array}{c}100 \mathrm{keV} \\
\mathrm{Ar}^{+}\end{array}$ & $\begin{array}{c}100 \mathrm{keV} \\
\mathrm{Cu}^{+}\end{array}$ & $\begin{array}{c}100 \mathrm{keV} \\
\mathrm{Kr}^{+}\end{array}$ \\
\hline $\begin{array}{l}\text { Low Temp } \\
\text { Irradiation }\end{array}$ & $(0.31) *$ & $\begin{array}{r}0.53 \\
\pm 0.05\end{array}$ & $\begin{array}{r}0.48 \\
\pm 0.03\end{array}$ & $\begin{array}{r}0.32 \\
\pm 0.02\end{array}$ & $\begin{array}{r}0.49 \\
\pm 0.04\end{array}$ & $\begin{array}{r}0.52 \\
\pm 0.04\end{array}$ \\
\hline $\begin{array}{l}\text { Room Temp } \\
\text { Irradiation }\end{array}$ & $\begin{array}{r}0.40 \\
\pm 0.04\end{array}$ & $\begin{array}{r}0.61 \\
\pm 0.03\end{array}$ & $\begin{array}{r}0.74 \\
\pm 0.03\end{array}$ & $\begin{array}{r}0.38 \\
\pm 0.04\end{array}$ & $\begin{array}{r}0.63 \\
\pm 0.03\end{array}$ & $\begin{array}{r}0.78 \\
\pm 0.03\end{array}$ \\
\hline Difference & $(29 \%)$ & $15 \%$ & $54 \%$ & $19 \%$ & $29 \%$ & $50 \%$ \\
\hline
\end{tabular}

*estimated from incomplete data. 
Table 2. Yield of dislocation loops per bombarding self ion at 50 and $130 \mathrm{keV}$ energies and temperatures of 30,300 and $600 \mathrm{~K}$.

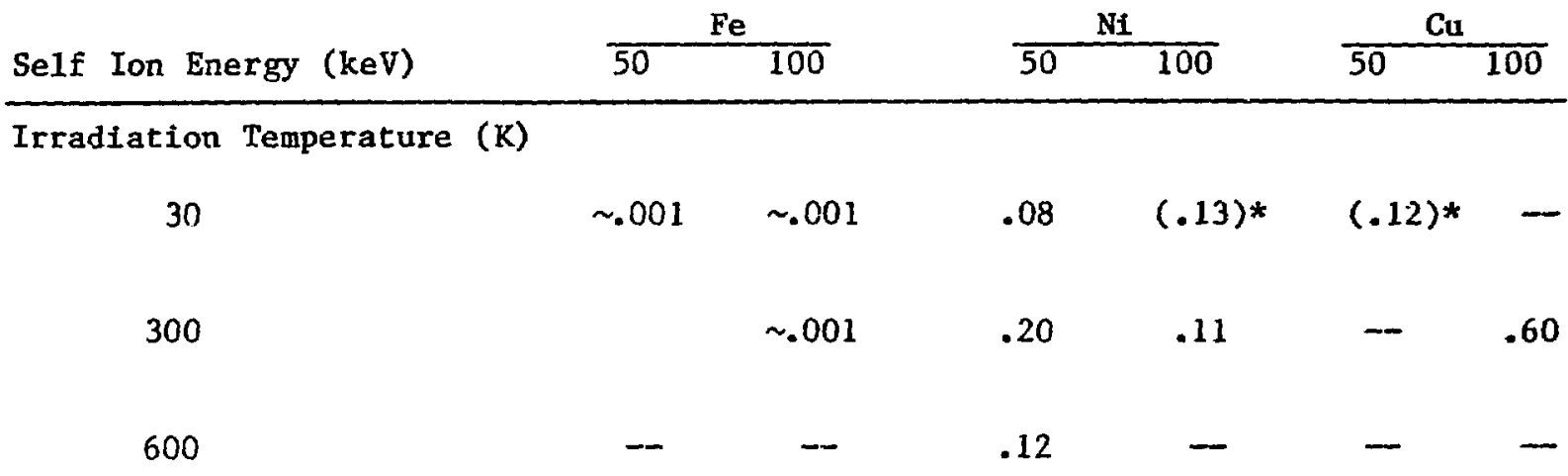

* Iimited data 


\section{Figure Captions}

Fig. 1. Matching of disordered zones with dislocation loops under various irradiation conditions:

a) $100 \mathrm{keV} \mathrm{Cu}^{+}$at $30 \mathrm{~K}$, recorded on the Argonne HVEM at low

b) $50 \mathrm{keV} \mathrm{Cu}+$ at $30 \mathrm{k}$, recorded on the JEM100B at room temperature

c) $50 \mathrm{keV} \mathrm{Ar}+$ at $30 \mathrm{~K}$, recorded on the JEM100B.

In each case a pair of micrographs of the same area is shown. The left micrograph is an image obtained in a $\bar{g}=\langle 110\rangle$ superlattice reflection, and shows disordered zones. The right is a bright-field kinematical image showing loops. Some loops and their associated disordered zones are ringed.

F.lg. 2. Dark field $(\bar{g}=\langle 200\rangle)$ micrograpli series illustrating increase in dislocation loop density in the same area in $\mathrm{Ni}$ with dose of seif ions at án energy of $100 \mathrm{keV}$ at a temperature of $300 \mathrm{~K}$. Arrowed loops are absent at next highest dose.

Fig. 3. Comparison of loop production in $\mathrm{Cu}$ and $\mathrm{Ni}$ during $100 \mathrm{keV}$ self-ion irradiations at a temperature of $300 \mathrm{~K}$.

Fig. 4. Dark field $(\bar{g}=\langle 200\rangle)$ micrograph series illustrating the increase in dislocation loop density in $\mathrm{Ni}$ during $50 \mathrm{keV}$ self-ion irradiation at a temperature of $30 \mathrm{~K}$, and upon annealing to $300 \mathrm{~K}$.

Fig. 5. Comparison of loop production in Ni during $50 \mathrm{keV}$ self-ion Irradiations at temperatures of 30,300 and $600 \mathrm{~K}$.

Fig. 6. Comparison of loop production in $\mathrm{Cu}$, $\mathrm{Ni}$ and Fe during $100 \mathrm{keV}$ selfion irradiations at a temperature of $300 \mathrm{~K}$.

Fig. 7. Comparison of loop production in $\mathrm{Ni}$ and Fe during $50 \mathrm{keV}$ self-ion irradiations at a temperature of $30 \mathrm{~K}$. 
a

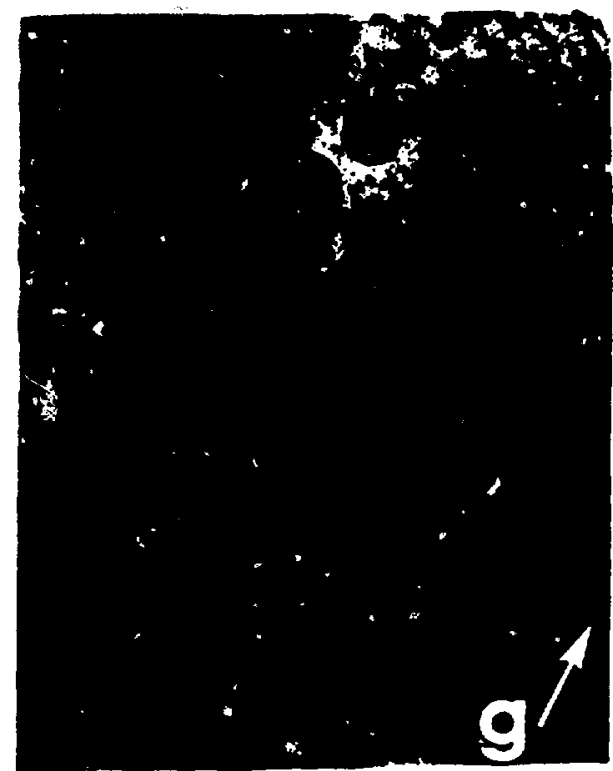

b $20.90+n^{2}$

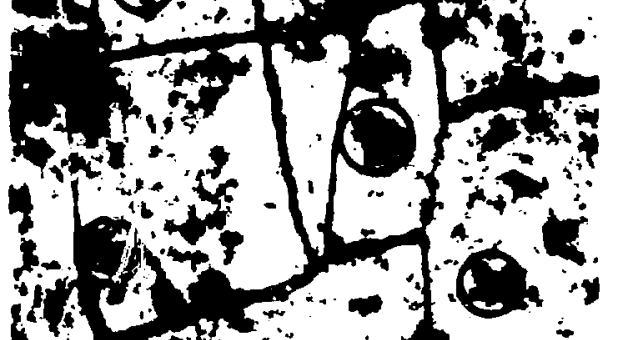

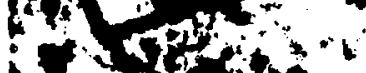

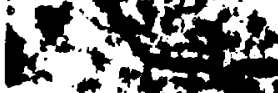

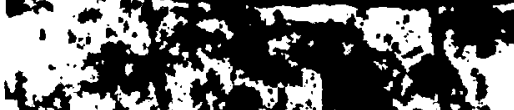

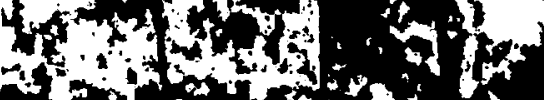
Antase $x^{2}=0$

$$
\therefore
$$
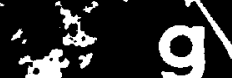

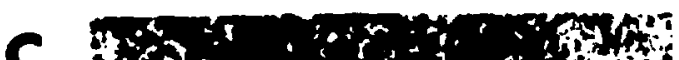

(c) Fo"

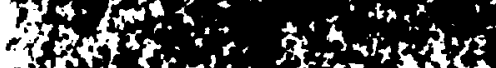

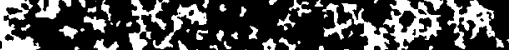

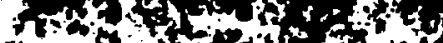

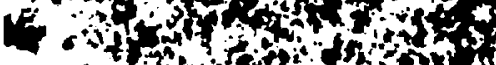

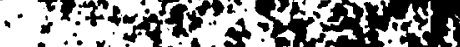

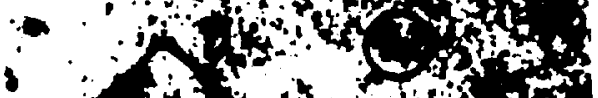

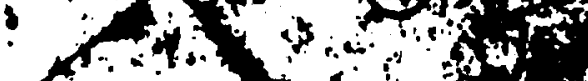

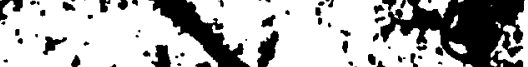

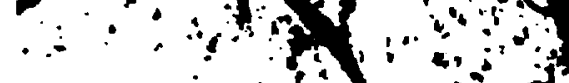

- 140

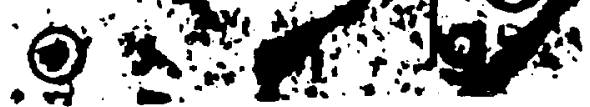

(1.)

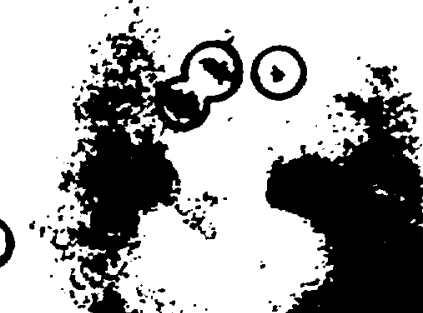

(E)
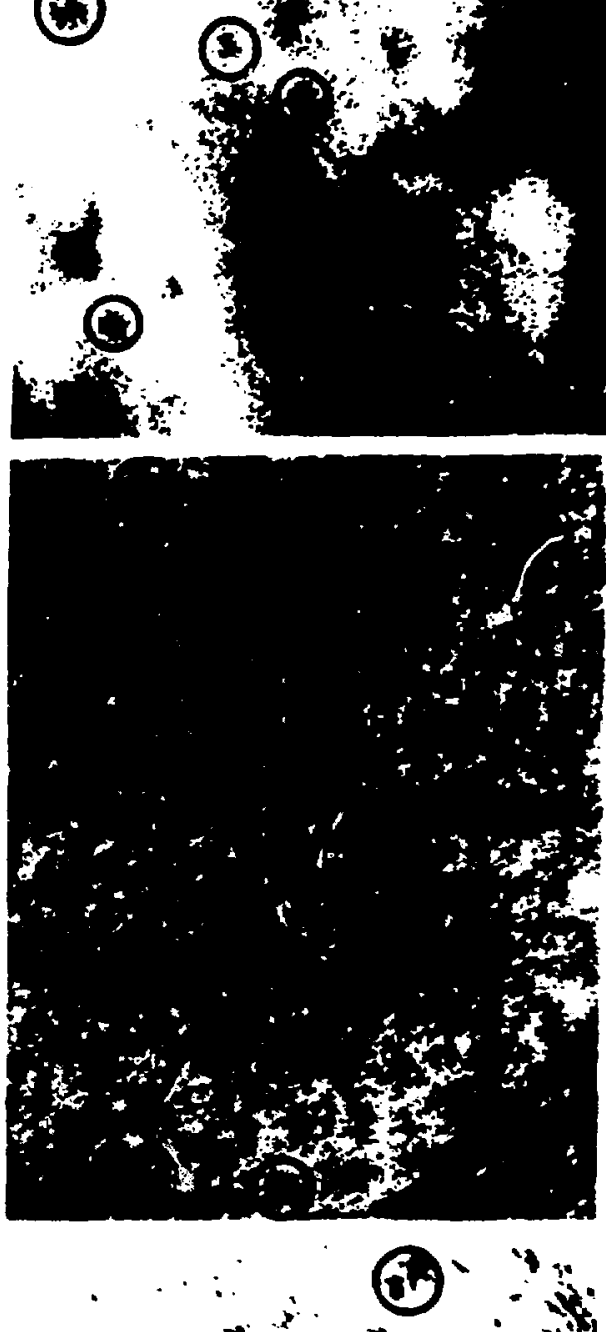

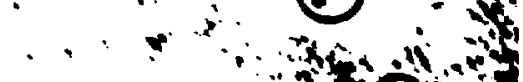

$$
\begin{aligned}
& \text {.. .. : * * }
\end{aligned}
$$

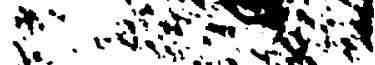

$$
\begin{aligned}
& 4 \times 10
\end{aligned}
$$

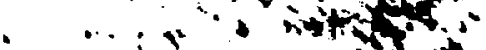

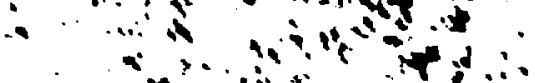

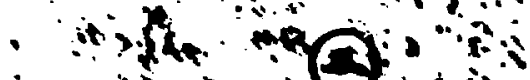

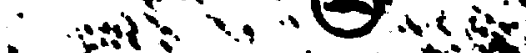$$
x^{-7}+2, \div
$$

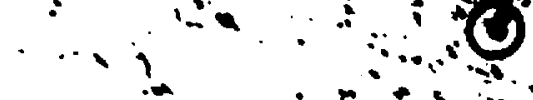

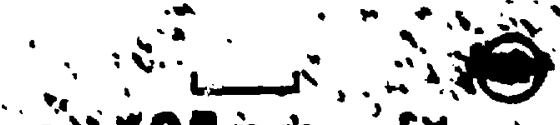

(9)

Fig. 1 


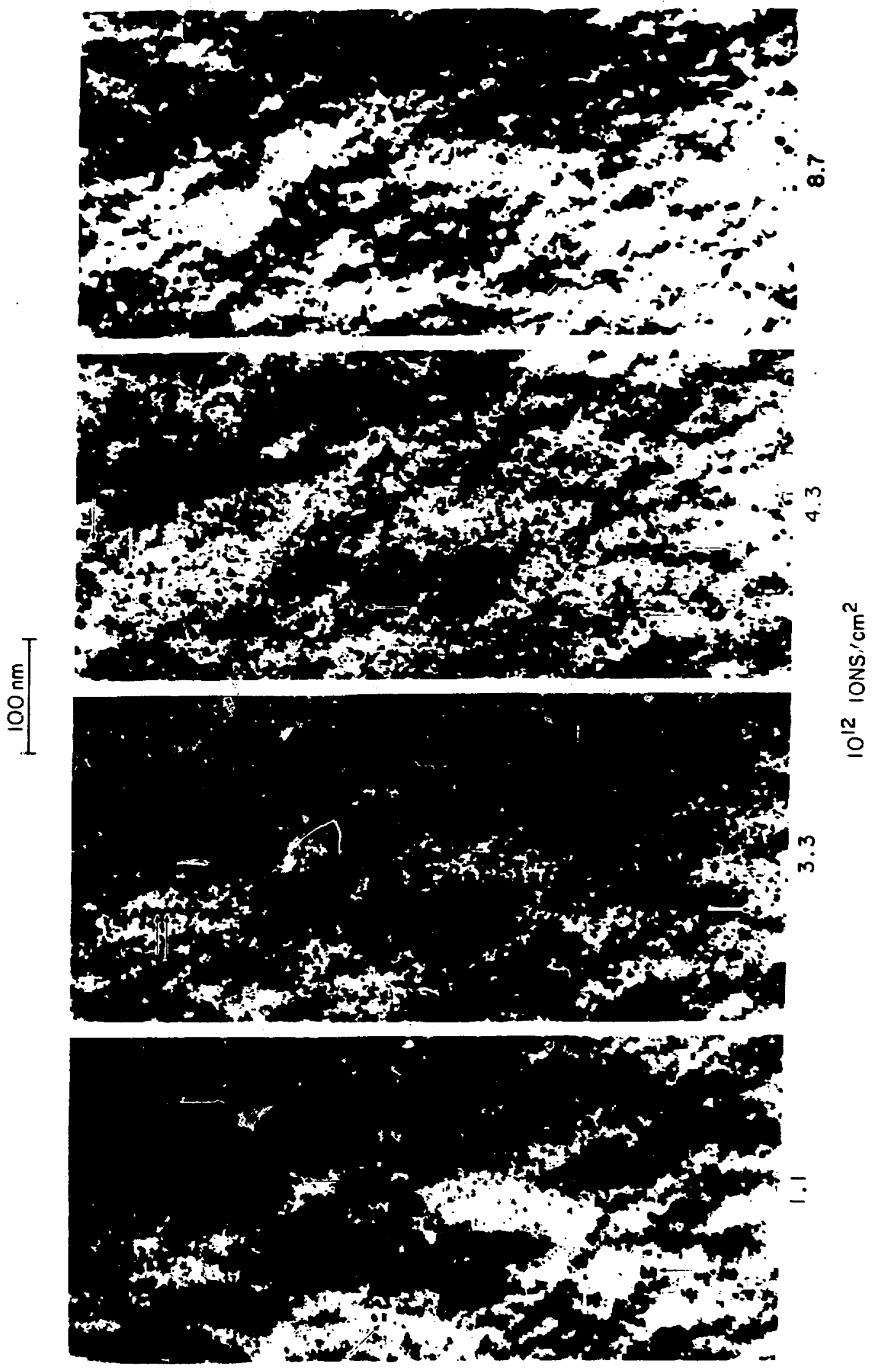




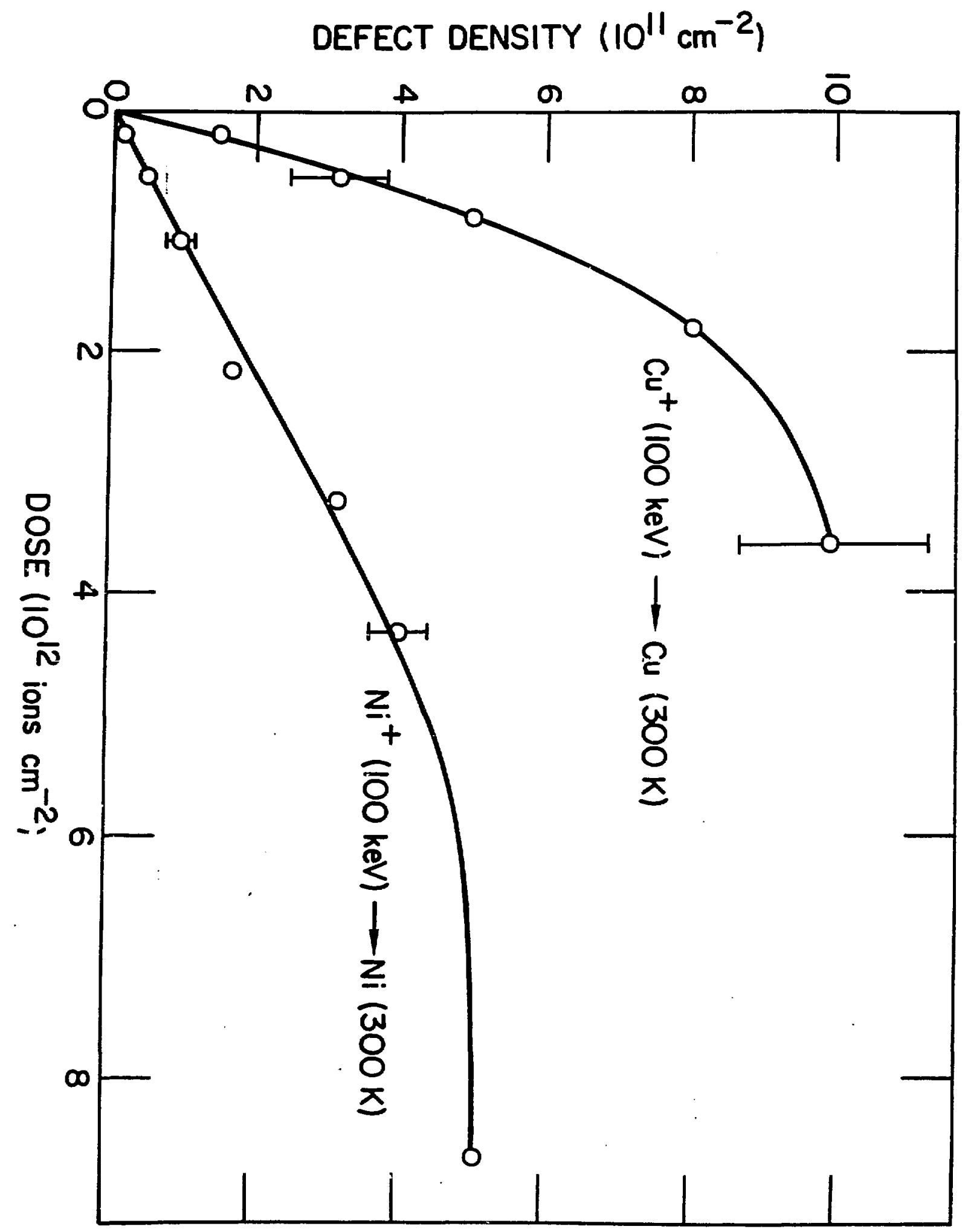

Fig. 3 

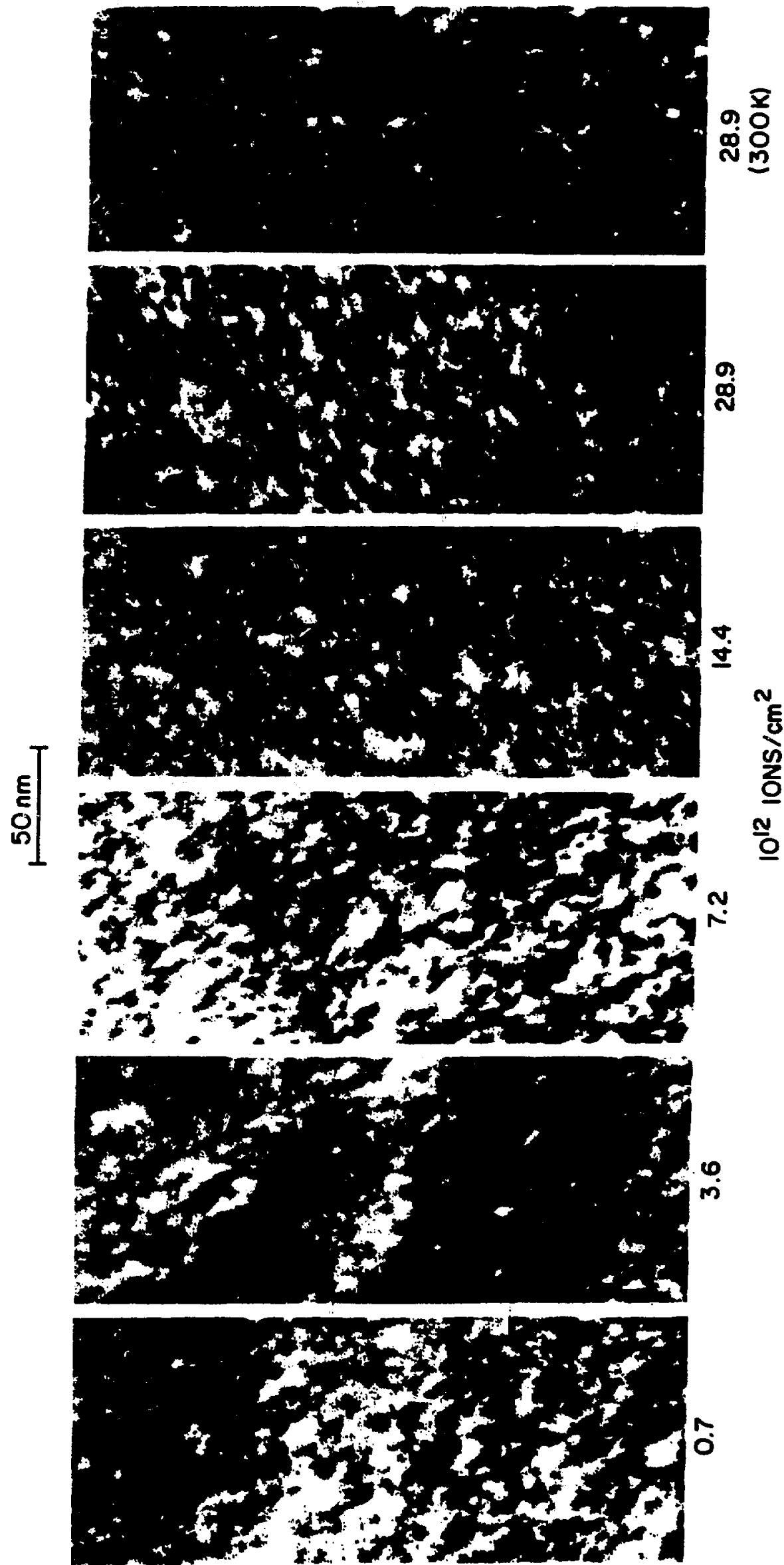


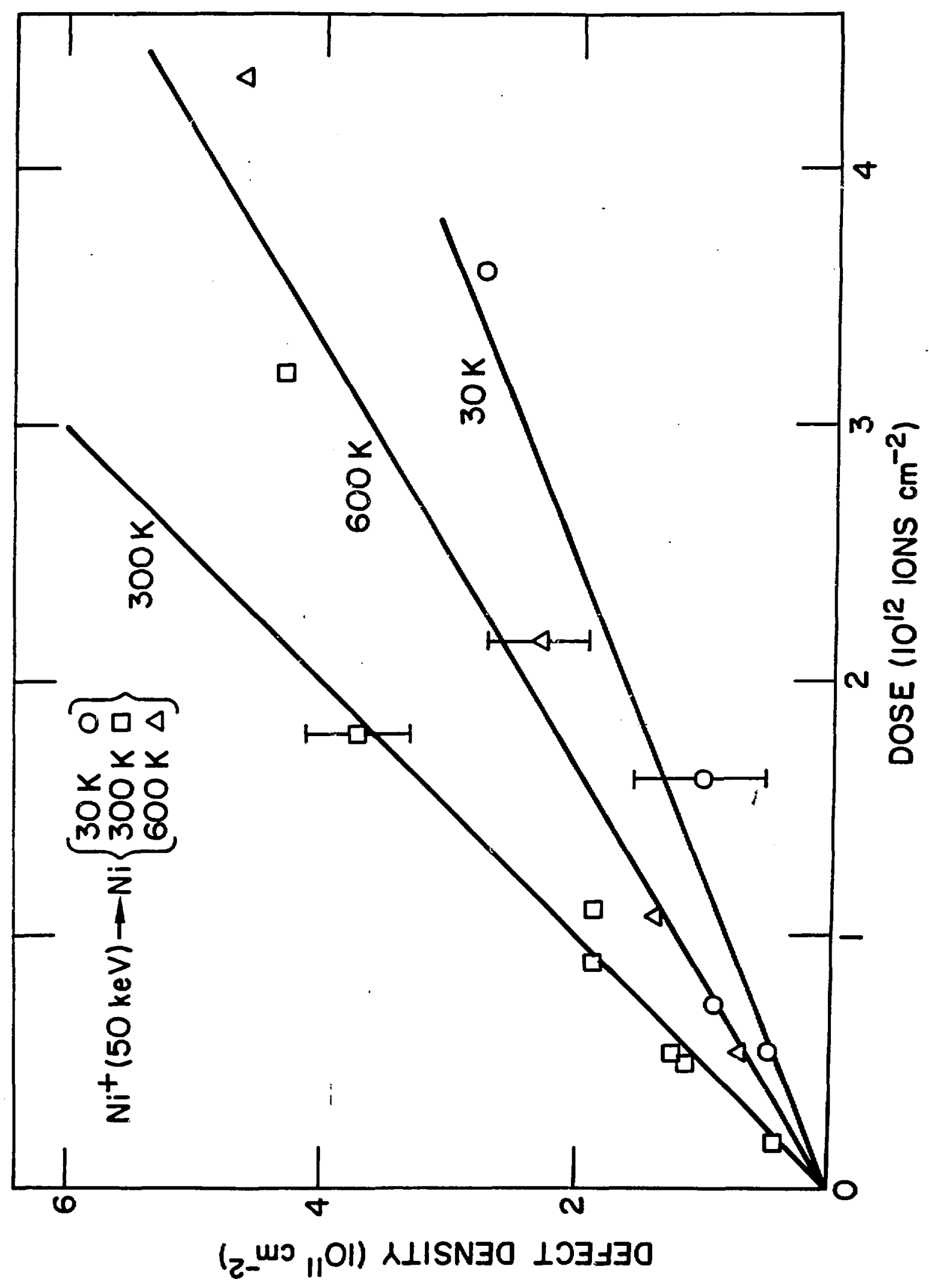




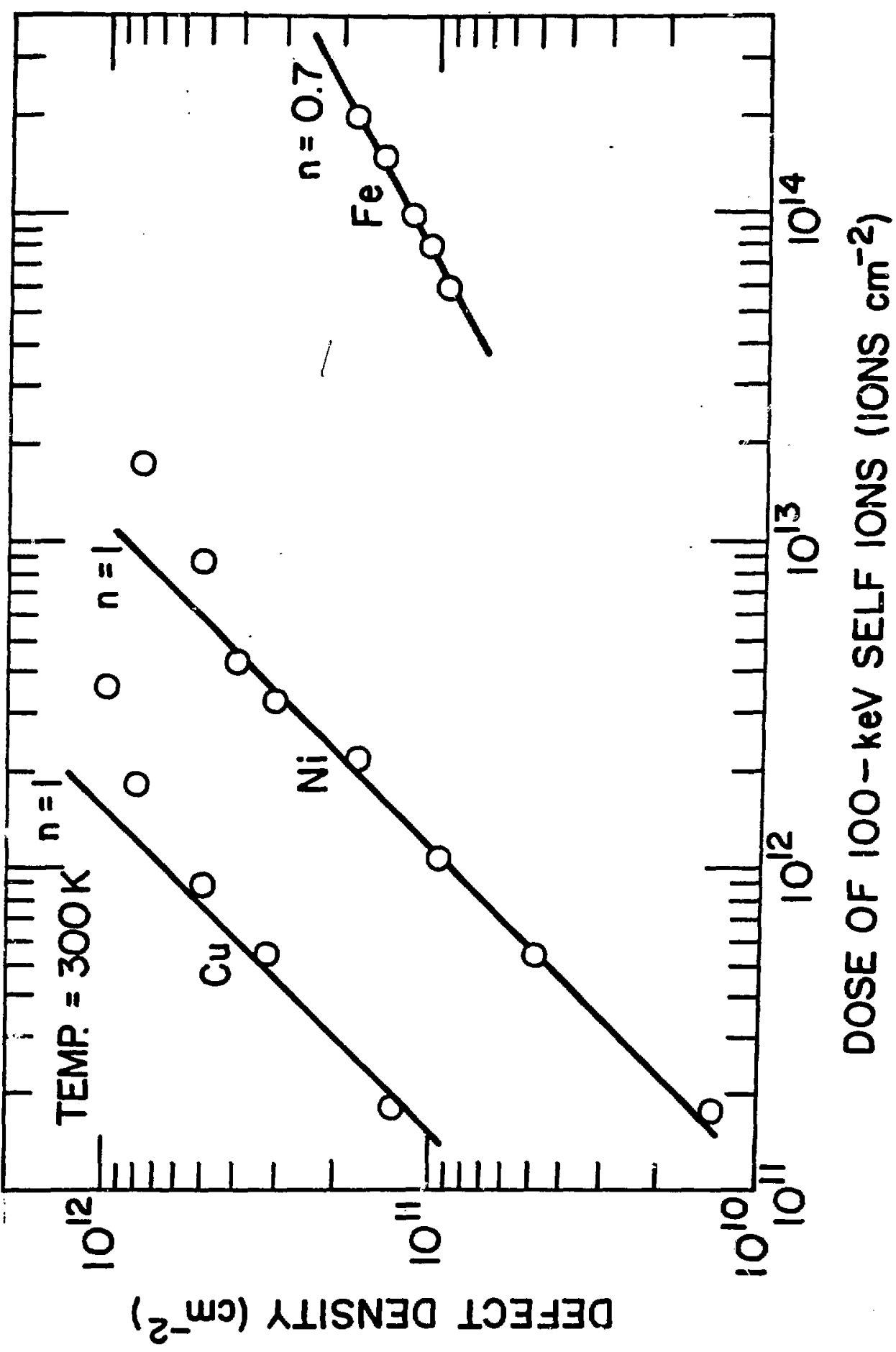




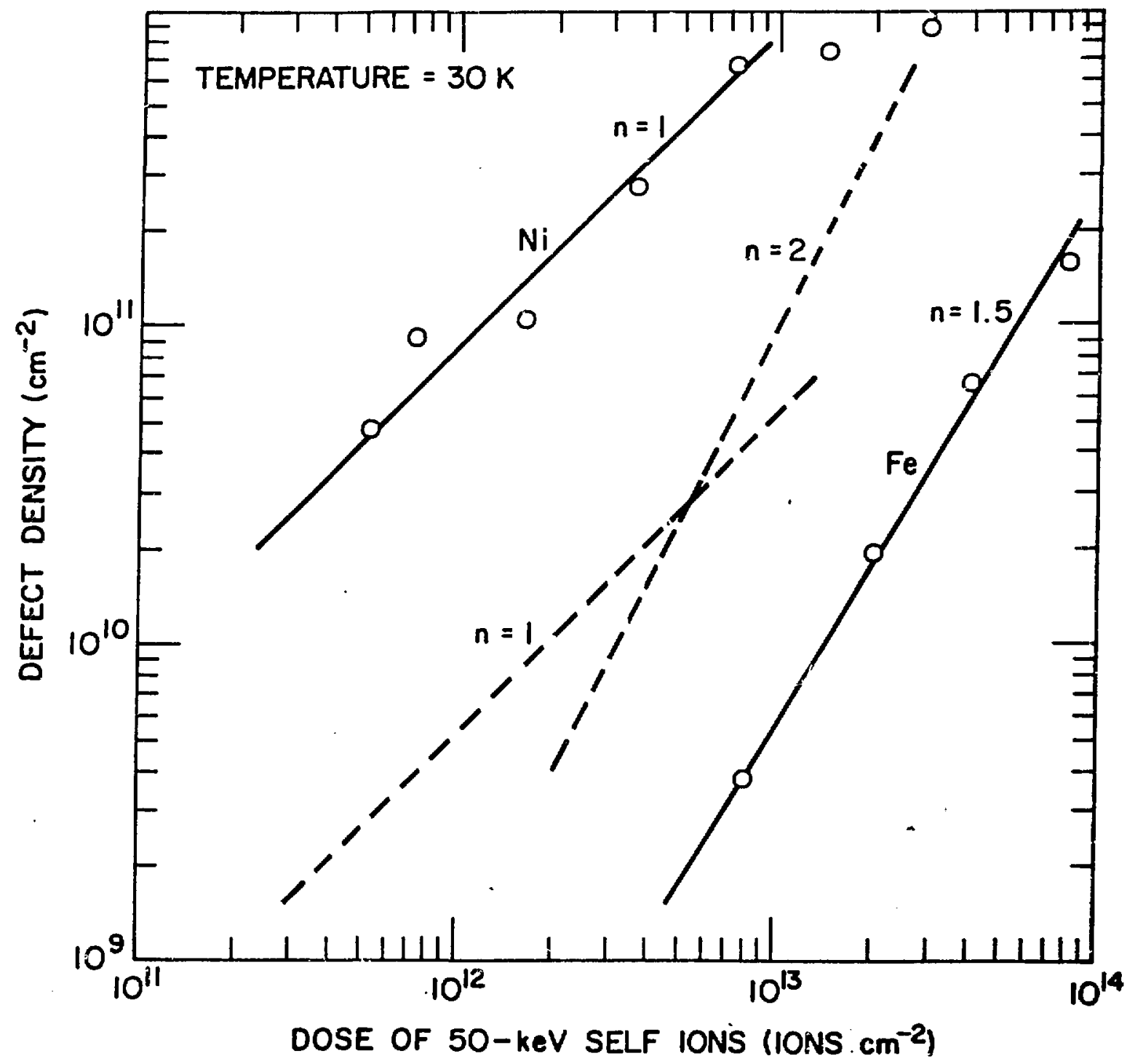

Fig. 7 